\title{
LOS DERECHOS FUNDAMENTALES SOCIALES Y LA PROTECCIÓN DE LA SALUD*
}

\author{
POR \\ GUILLERMO ESCOBAR ROCA \\ Profesor Titular de Derecho Constitucional \\ Universidad de Alcalá
}

\section{LA DOGMÁTICA DE LOS DERECHOS FUNDAMENTALES SOCIALES}

La dogmática de los derechos fundamentales sociales (término este preferible al de «derechos económicos, sociales y culturales», de excesivo sesgo internacionalista) es todavía una tarea pendiente en España. Normalmente, cuando se trata de esta cuestión se sitúa en primer plano el problema de su justiciabilidad o, en términos más amplios y sin duda preferibles, de su exigibilidad: hay un déficit de garantía, que es preciso resolver. Es decir, en los planteamientos dominantes sobre los derechos sociales todo acaba centrándose en una parte de esta amplia temática, seguramente posterior y complementaria de la principal.

A nuestro juicio, previamente al planteamiento del problema de las garantías es preciso construir una dogmática articulada en torno al concepto, fundamento, estructura, contenido, sujetos, intervenciones y límites de este tipo de dere-

* Resumen del capítulo II y de los apartados 1 a 4 y 6 del capítulo IX del libro colectivo dirigido por G. ESCOBAR ROCA, Derechos sociales y tutela antidiscriminatoria (publicación prevista para mayo de 2008). Por razones de síntesis queda fuera el análisis de las garantías (de los derechos fundamentales sociales en general y del derecho a la salud en particular), abordadas con profundidad en el libro citado. 
chos. Esa dogmática debe poder ser aplicada, sin excesiva dificultad, al análisis de las figuras concretas; de ahí que este trabajo se divida en dos partes: una parte general y su aplicación a un supuesto particular. Partes general y especial de los derechos fundamentales deben construirse conjuntamente: cualquier dogmática, por bien construida que estuviera, resultaría inútil si no sirviera para analizar mejor las figuras concretas.

Por otra parte, debe intentarse construir una dogmática general de los derechos sociales que camine, en la medida de lo posible, por las mismas vías que la dogmática de los derechos de defensa, la cual se encuentra ya relativamente consolidada ${ }^{1}$. De esta forma se consiguen resultados beneficiosos para los derechos sociales: por un lado, se rompe el consolidado perjuicio que minusvalora estos derechos, como distintos (e inferiores) a los "clásicos» $\mathrm{y}$ "auténticos» derechos liberales $^{2}$; por otro, en la medida en que se mantienen las estructuras lógicas del pensamiento dominante, se facilita el consenso doctrinal sobre los derechos sociales $^{3}$.

La problemática característica de los derechos sociales se plantea cuando estos presentan la estructura típica de los derechos de prestación. Los derechos fundamentales sociales de prestación (en adelante, para abreviar, derechos sociales) son aquellos que estructuralmente exigen, ante todo (no cabe descartar una faceta defensiva complementaria), que el obligado por el derecho suministre a su titular prestaciones económicamente cuantificables, que también podrían obtenerse a través del mercado.

1 Esta es la perspectiva del muy difundido libro de R. ALEXY, Teoría de los derechos fundamentales, CEC, Madrid, 1993, donde los derechos sociales se incorporan con toda naturalidad a la nómina de los derechos fundamentales (vid. esp. pp. 482-501), planteamiento que yo mismo he seguido en G. ESCOBAR ROCA, Introducción a la teoría jurídica de los derechos humanos, Trama, Madrid, 2005, esp. pp. 58-62. Entre los pocos trabajos que desarrollan con algún detalle esta idea puede citarse R. ARANGO (discípulo por cierto de ALEXY), El concepto de derechos sociales fundamentales, Legis, Bogotá, 2005, esp. pp. 30-113.

2 Un importante trabajo reciente se dirige precisamente a desmontar las falacias de este pensamiento dominante, que minusvalora los derechos sociales: G. PISARELLO, Los derechos sociales y sus garantías, Trotta, Madrid, 2007.

3 Si queremos movernos dentro de la dogmática (otra cosa sería un planteamiento de Filosofía o Teoría política, donde toda crítica está permitida), habremos de ser necesariamente (al menos en cierto modo) conservadores, y ello en un doble sentido: en primer lugar, sólo podemos argumentar en el marco del Derecho vigente (el Derecho es dúctil — por usar la conocida traducción a ZAGREBELSKY - pero sólo hasta cierto punto); en segundo lugar, se debe intentar convencer a la comunidad jurídica (¿para qué razonar en el desierto?), y esta no se va a dejar convencer fácilmente. Conectando esta necesidad de convencer (menos importante sin duda en otras épocas) con la sociedad democrática, últimamente, p. ej., M. ATIENZA, El Derecho como argumentación, Ariel, Barcelona, 2006, pp. 247 y ss. 
Conectando el Pacto Internacional de Derechos Económicos, Sociales y Culturales (en adelante, PIDESC) con la Constitución Española (en adelante, $\mathrm{CE}$ ) nos encontramos con que los derechos sociales son, sobre todo, los seis siguientes: derecho al trabajo (lo que incluye un trabajo con unas determinadas condiciones), derecho a la seguridad social, derecho a la vivienda, derecho a la protección de la salud, derecho a la educación y derecho a la cultura.

La protección de colectivos (niños, mujeres, mayores o situaciones de dependencia, por citar sólo los mencionados, directa o indirectamente, en la CE) no suele articularse, por el momento, con la forma de derecho social.

¿De qué derechos hablamos cuando hablamos de derechos sociales? Desde la perspectiva española, los derechos sociales son, primero, los derechos fundamentales (esto es, los reconocidos en la Constitución) y sólo después (y, desde luego, complementariamente) los derechos humanos (o, más exactamente, los derechos de Derecho internacional). Este punto de partida se justifica porque, según la opinión predominante (que aquí no voy a discutir) en España la Constitución tiene primacía sobre los tratados internacionales y porque los mecanismos de protección internacional de los derechos son siempre subsidiarios de los nacionales.

Como adelantábamos, el problema de la exigibilidad de los derechos sociales ha de resolverse, antes que nada, con la ayuda de una buena dogmática jurídica. Las dificultades para la efectividad de los derechos sociales son, en primer lugar, ideológicas. Existe una amplia conciencia, en la doctrina jurídica dominante, sobre la menor importancia de los derechos sociales (en relación con los liberales), que en muchas ocasiones lleva incluso a negar que se trate de auténticos derechos ${ }^{4}$. Cuando son considerados como tales, se reducen considerablemente su contenido (bajo la excusa de lo económicamente posible) y sus garantías (aduciéndose, por lo general, que los tribunales no pueden pronunciarse sobre cuestiones de política social).

En la actualidad, la consolidación de la Constitución normativa (exigible judicialmente de forma directa, incluso frente al legislador) facilita (o debería facilitar) mucho las cosas: la norma suprema como elemento transformador ${ }^{5}$.

${ }^{4}$ Denunciando la ideología subyacente, G. PISARELLO, Los derechos..., cit., p. 14 y passim. En sentido similar, C. DE CABO, Teoría constitucional de la solidaridad, Marcial Pons, Madrid, 2006, pp. 16, 20 y 53. Lamentablemente, ni uno ni otro personalizan sus críticas.

5 Esta función de la Constitución, consustancial a un entendimiento de la misma acorde con el Estado social (y yo diría más: acorde con el siglo XXI), se encontraba presente en el momento fundacional (si la izquierda votó la Constitución lo hizo con esa condición) y resulta evidente a lo largo y ancho de su articulado, salvo para quien no quiera verlo. Entre la escasa bibliografía española al respecto, L. VILLACORTA MANCEBO, «La Constitución como «tarea», la optimización de los derechos fundamentales como resultado en el Estado de bienestar", Revista de las Cortes Generales, n. ${ }^{\circ} 37,1996$, pp. 231 y ss. 
El acento ha de ponerse entonces en el análisis de la Constitución y los juristas especializados en Derecho constitucional tienen en sus manos la responsabilidad de subvertir la ideología dominante y preparar el camino hacia una mayor efectividad de los derechos sociales. Ahora bien, un estudio aislado de las normas constitucionales, de resultar posible (una especie de «teoría pura del Derecho constitucional») resultaría inútil y, lo que es peor, engañoso, por ocultar algo tan importante como la propia Constitución: el desarrollo constitucional. Deben por tanto analizarse también otras normas relevantes, y para determinar esta relevancia debe atenderse al grado de relación (mayor o menor) de la norma con el contenido de la Constitución formal. Deberá hablarse por tanto de normas (pues de Derecho vamos a hablar) que cumplen (o incumplen, que esto es igual de importante) la Constitución, con independencia de su rango. La determinación de este conjunto normativo difícilmente puede concretarse en abstracto; dependerá de la previa construcción doctrinal que se defienda.

A mi juicio, una dogmática útil para los derechos sociales debería adoptar seis pautas metodológicas mínimas:

1) Hay que construir, "hacer doctrina», sin temor a ser originales y sin apoyarse sólo en la jurisprudencia (no se olvide que no es función de los tribunales hacer dogmática). No conviene, sin embargo, «inventar» demasiado. Como señalábamos, si es posible deben utilizarse las técnicas conocidas y aplicarlas a nuestro ámbito, con las modulaciones necesarias. Raramente una concepción totalmente original va a ser aceptada. Lo primero es aportar claridad (luego hablaremos de la importancia del análisis estructural) y seguridad.

2) Si la teoría pura del Derecho es imposible, la teoría pura del Derecho constitucional es inútil y enmascaradora. Es obligado acudir a otras disciplinas para tratar esta materia, y muy en especial a la Filosofía del Derecho, a la Sociología del Derecho y, sobre todo, a la Sociología general. Es más útil leer Informes sociológicos, del Defensor del Pueblo o de organismos internacionales (absolutamente imprescindibles los emanados del Comité de Derechos Económicos, Sociales y Culturales) que sesudos tratados de doctrina.

3) La consideración histórica de los derechos sociales tiene una importancia relativa para la dogmática. Si la tarea central de la dogmática es interpretar y si los derechos sociales son, además de relativamente recientes, transformadores de la Historia, el método histórico resulta inadecuado. En principio, podría ser útil para conocer y explicar el sentido de los derechos (algo necesario para la dogmática más teórica e incluso, en ocasiones, para la interpretación, al conectar con el método teleológico) pero quizás contraproducente, pues no parece que hoy 
pueda defenderse la clásica interpretación de los derechos sociales como derechos de la clase trabajadora ${ }^{6}$.

4) Hay que ser útiles (los operadores jurídicos quieren respuestas a sus problemas). Teoría y praxis son inescindibles en el mundo del Derecho. Hay que conocer los problemas (contactando incluso directamente con la realidad) y ordenar la argumentación con miras a solucionarlos. Es preciso conocer la jurisprudencia, pero no para seguirla a ciegas sino para saber dónde están los problemas y, sobre todo, las inseguridades.

5) Hay que argumentar bien, seria y jurídicamente (la dogmática se distingue de la Filosofía y, desde luego, de la acción política), sobre la base de los principios constitucionales (en los términos que después se verán) pero dejando claro, en su caso (esta es, desde luego, mi perspectiva) que van a defenderse tesis a favor de la mejor efectividad de los derechos sociales. No es bueno ser extremista (siempre hay que reconocer el valor de otras posiciones) pero tampoco engañar al "público» diciendo que la dogmática es neutral. La dogmática debe ser consciente y moderadamente militante.

6) El punto de vista constitucional (como perspectiva distinta a la positivista tradicional, todavía dominante) se traduce, sobre todo, en una cosa: analizar críticamente la ley. Raramente encontraremos omisiones absolutas pero con mucha frecuencia vamos a encontrar leyes oscuras (aquí sobre todo debemos aportar claridad) y cicateras en materia de derechos sociales. La crítica jurídica interna (contraste con la Constitución y el Derecho internacional) es más útil, porque permite conseguir cosas con las armas del propio Derecho.

\section{PRESUPUESTOS DE UNA TEORÍA DE LOS DERECHOS SOCIALES CONSTITUCIONALMENTE ADECUADA}

La consideración analítica o estructural de la Constitución apenas ha sido desarrollada por la dogmática, y esto es una falla grave. Buena parte de los problemas jurídicos son pseudoproblemas y podrían evitarse con mínimas precisiones previas sobre la estructura de las normas. La primera función del científico es dar claridad (saber de qué hablamos y qué queremos decir, saber cuándo describimos, cuándo interpretamos, cuándo criticamos y cuándo proponemos cambios normativos) y esta muchas veces no se encuentra. Además, sinceramente

${ }^{6}$ Buenos argumentos al respecto en F. J. CONTRERAS Peláez, Derechos sociales: teoría e ideología, Tecnos, Madrid, 1994, pp. 32 y ss. y en V. ABRAMOVICH y C. COURTIS, El umbral de la ciudadanía. El significado de los derechos sociales en el Estado social constitucional, Ediciones del Puerto, Buenos Aires, 2006, pp. 33 y ss. 
pienso que si identificamos bien las estructuras (tipos de normas) habremos dado bastantes pasos no sólo para ahondar en el conocimiento de la Constitución sino también para favorecer su cumplimiento.

Todas las normas constitucionales pueden reducirse a cuatro categorías: principios constitucionales nucleares, normas de organización y procedimiento, mandatos constitucionales y derechos fundamentales ${ }^{7}$. Todas ellas están relacionadas entre sí. En la materia que nos ocupa, es preciso realizar distinciones (evitar generalizaciones) y acentuar la eficacia (sobre todo interpretativa) de los principios y la exigibilidad de los mandatos (categoría esta todavía poco definida; de hecho, en la práctica operan casi como normas programáticas).

La escasa dogmática que se ha ocupado de los derechos sociales comete errores importantes por falta de claridad en sus presupuestos estructurales. El error más grave y común es el de «meter a todos los derechos sociales en el mismo saco» ${ }^{8}$. Se impone, ante todo, establecer clasificaciones estructurales a partir de las diferencias apreciables en el mismo texto. En la Constitución encontramos, entre otras cosas, derechos (p. ej., arts. 27.1, 43.1, 44.1 in fine o 47, primera frase) y mandatos que concretan el carácter objetivo de los derechos (p. ej., arts. 27.5, 43.2, 44.1 al comienzo o 47, 2a frase), pero también mandatos que, al menos desde una primera lectura, no guardan relación con derechos (p. ej., arts. 39, 49 o 50 ).

Debe darse preferencia a las normas más vinculantes y mejor relacionadas con la dignidad de la persona (principio nuclear de nuestra Constitución: de «fundamento del orden político» habla el art. 10.1), esto es, a los derechos fundamentales. No pretendo, desde luego, sostener que la única (ni siquiera la mejor) forma de luchar por la justicia social sea crear derechos subjetivos. Simplemente, es una de las formas posibles y hay que afirmarla y potenciarla, no negarla de raíz?

7 Para una primera aproximación a las diferencias entre ellas, G. ESCOBAR ROCA, Introducción..., cit., pp. 40-45.

${ }^{8}$ En España, los cultivadores de la filosofía del Derecho, aun cuando a veces citan la CE, suelen realizar generalizaciones sobre los derechos sociales, prescindiendo de las ostensibles diferencias entre las correspondientes normas de reconocimiento: vid., p. ej., F. J. LAPORTA, «Los derechos sociales y su protección jurídica: introducción al problema», en Constitución y derechos fundamentales, CEPC, Madrid, 2004, pp. 297 y ss. o A. E. PÉREZ LuÑO, «La positividad de los derechos sociales: su enfoque desde la Filosofía del Derecho", Derechos y libertades, n. ${ }^{\circ} 14,2006$, pp. 151 y ss. Sin necesidad de entrar a analizar las tesis de fondo defendidas por estos u otros autores, su planteamiento metodológico podría ser válido, quizás, desde la Filosofía del Derecho pero no lo es, evidentemente, desde la dogmática jurídica, que exige diferenciar donde el Derecho diferencia.

${ }^{9}$ Ilustrativas, al respecto, las respuestas, que en su conjunto suscribo, de J. A. RUIZ PARCERO y C. Bernal Pulido al trabajo de F. ATRIA "¿Existen derechos sociales»?, crítico este con la posibilidad de «derechos jurídicos» sociales. Todo ello en Doxa. Discusiones, n. ${ }^{\circ}$ 4, 2004. 
Algunas consecuencias de la aproximación que propongo podrían ser las siguientes: construir las figuras del catálogo de los derechos sociales según la estructura típica de los derechos fundamentales y posibilitar el tránsito de lo objetivo a lo subjetivo (mandatos antes objetivos pueden después exigirse por los particulares) ${ }^{10}$, así como la recíproca confluencia entre ambas dimensiones, pero con prioridad de la subjetiva ${ }^{11}$.

En general en la dogmática jurídica, y con mayor motivo en el tema que abordamos, detrás de las grandes cuestiones y afirmaciones se encuentra la precomprensión del jurista o, dicho en términos más ampulosos, su concepción de la sociedad, el Estado y la Constitución ${ }^{12}$. Siendo esto así, mejor será reconocer cuáles son esos presupuestos ${ }^{13}$, pues si no los dejamos entrar al principio por la puerta después penetrarán, a escondidas, por la ventana.

Un típico problema de la dogmática, difícilmente evitable, es tratar los temas desde una sola perspectiva (exceso de especialización), olvidando su contexto. Otro problema es, no sólo la ya denunciada ocultación de la precomprensión sino, cuando más o menos esta se justifica, el escaso desarrollo de dicha justificación ${ }^{14}$. Aquí tratamos de mitigar (no es posible eliminarlos del todo) ambos problemas, mediante la afirmación de las tesis (o mejor, esbozo de tesis) siguientes, ordenadas según su relación con los que podríamos llamar subsistemas constitucionales más relevantes, haciendo paralela mención a alguna de sus consecuencias para nuestro tema:

1) La Constitución orgánica. La división de poderes (o, como resulta seguramente más correcto, la triple reserva de legislación, administración y jurisdicción) exige hoy el respeto al ámbito propio de cada cual. Dejando fuera el con-

${ }^{10}$ Así sucede, p. ej., con el mandato del art. 41 CE, que, a la vista del Derecho internacional (vinculante para el intérprete $e x$ art. 10.2 CE), permite incluir un derecho fundamental a la seguridad social, o con los mandatos de acción afirmativa implícitos en los arts. 39, 49 o 50, que en su desarrollo legislativo se han concretado, al menos en parte, en posiciones individuales judicialmente accionables.

11 Sobre las razones de esta prioridad, G. EsCOBAR RocA, Introducción..., cit., pp. 45-49.

12 Cuestión esta obvia pero casi siempre silenciada. Por todos, K. HESSE, Escritos de Derecho constitucional, CEC, Madrid, 1983, p. 44, con obligadas referencias a GADAMER y a MÜller.

${ }^{13}$ Modélico al respecto, E. STEIn, Staatsrecht, Mohr, Tubinga, 13. ${ }^{a}$ ed., 1991, esp. p. 379.

${ }^{14}$ Vid., p. ej., A. FernándeZ-Miranda CAMPOAmor, "El Estado social», Revista Española de Derecho Constitucional, n. ${ }^{\circ}$ 69, 2003, esp. pp. 168 y ss., donde se explicita la precomprensión (lo cual implica un avance importante) pero esta apenas se desarrolla. El autor, sin embargo, remite a otro trabajo suyo sobre su concepción de la Constitución. 
trol judicial de la Administración, generalmente poco problemático ${ }^{15}$, las hipótesis de conflicto entre poderes son en la práctica residuales y no es lícito construir la Constitución orgánica a partir de lo anecdótico. Las tesis de la confrontación legislación-administración y legislación-jurisdicción que otorgan primacía incondicionada al poder legislativo no son correctas: un Estado social fuerte exige una Administración fuerte y unos tribunales fuertes. En especial, la Constitución normativa exige un mayor poder de los tribunales en todas las materias, pero especialmente en materia social; obviamente, se trata de un problema histórico y gradual, no de defender que los jueces decidan la política social. El argumento de la falta de legitimación democrática de los jueces se combate desde la propia división de poderes: si los tribunales son un poder, deben ejercer su poder. Lo que hay detrás de la crítica es una visión unilateral de la democracia (democracia es sólo el Parlamento), además de ingenua (el Parlamento decide democráticamente), y un prejuicio social hacia los jueces, mal disimulado. Si la Constitución es Derecho, tiene que ser aplicada por los órganos naturales de aplicación del Derecho. Como casi siempre, el problema es el de un eventual exceso, sirviendo como antídoto el principio de corrección funcional ${ }^{16}$.

2) La Constitución internacional. Los tratados internacionales (entre los que destaca el PIDESC) y la interpretación de los mismos por los órganos competentes para ello tienen, en cierto modo, valor (no hablo de rango) superior a la ley, en virtud del artículo 10.2 CE. No es doctrinalmente serio (en la fase en que estamos de globalización) ni jurídicamente correcto (interpretación sistemática externa) seguir determinando el contenido y las garantías de los derechos sociales al margen de este contexto internacional. Aunque ya no resulte jurídicamente obligado, deben tenerse en cuenta también otros documentos internacionales sin naturaleza de tratados.

3) La Constitución económica y financiera. Las normas constitucionales de contenido social son determinantes para la determinación de la Constitución económica característica del Estado social, la cual no es neutral. Los derechos económicos individuales (propiedad privada y libertad de empresa) tienen en la estructura de la Constitución un peso menor que los derechos sociales: los pri-

${ }^{15}$ El conocido debate entre iusadministrativistas sobre el tema concluyó en tablas. Quienes durante algunos años hemos desempeñado funciones judiciales en el ámbito contencioso-administrativo sabíamos que se trataba de un pseudoproblema, no diferente al problema mismo de la interpretación judicial. Vid., al respecto, M. ATIENZA, «Sobre el control de la discrecionalidad administrativa. Comentarios a una polémica», Revista Española de Derecho Administrativo, n. ${ }^{\circ} 85$, 1995 , pp. 5 y ss.

16 En el sentido de K. HeSSE, Escritos..., cit., pp. 49-50. 
meros no derivan directamente de la forma constitucional del Estado y conectan peor (aunque esto lo discutiría un liberal) con el núcleo duro de la dignidad humana. En cuanto a la Constitución financiera, debe destruirse el dogma de la plena competencia del legislador para la fijación del gasto público vía presupuestos (dogma destruido, por cierto, en la práctica, por cuanto con frecuencia han de ejecutarse gastos para cumplir sentencias judiciales, que exceden las previsiones presupuestarias): la ley anual de presupuestos debe ceder también ante la necesidad de satisfacer las demandas sociales (que derivan directamente del Estado social y de la dignidad de la persona).

4) La Constitución de los derechos. No puede construirse un sistema de derechos fundamentales que no integre en su seno, al mismo nivel que los demás, los derechos sociales. Para la estructura de la Constitución, tan importantes son unos como otros. Una distinta configuración (en su caso) de las garantías no puede hacer olvidar el dato esencial de que los derechos sociales derivan, tan directamente o más que los derechos liberales, de los principios constitucionales nucleares.

El sistema constitucional debe reconstruirse a partir de sus principios nucleares. Cualquier argumentación seria de dogmática constitucional debe explicitar su concepción de los mismos. No creo que la Constitución refleje un orden de valores. Tampoco creo que los principios sean demasiado importantes (aunque deberían serlo) en la práctica del Derecho; son seguramente más útiles para su comprensión y enseñanza. Hasta ahora, apenas han servido para reforzar el cumplimiento de la Constitución social pero creo que pueden y deben servir en el futuro a este fin, especialmente para reforzar interpretaciones que caminen en esa dirección.

Los tres principios constitucionales que guardan directa relación con los derechos sociales son, por este orden:

1) Dignidad. Uno de los mejores argumentos para defender los derechos sociales es demostrar su conexión con el principio de dignidad humana ${ }^{17}$. Buena parte de los filósofos que, desde finales del siglo XX, se han ocupado del tema destacan esta conexión, normalmente por la vía de relacionar libertad con igual disfrute de la libertad ${ }^{18}$, minimizando así las diferencias (si es que

${ }^{17}$ En el FJ 8 de la STC 236/2007, se destaca, creo que por vez primera en la jurisprudencia, la «inequívoca vinculación del derecho a la educación con la garantía de la dignidad humana, dada la innegable trascendencia que aquélla adquiere para el pleno y libre desarrollo de la personalidad y para la misma convivencia en sociedad».

18 P. ej., E. Tugendhat, Lecciones de ética, Gedisa, Barcelona, 1997, pp. 344 y ss. o J. González Amuchastegui, Autonomía, dignidad y ciudadanía. Una teoría de los derechos sociales, Tirant lo Blanch, Valencia, pp. 496 y ss. Para nuevos argumentos en esta misma dirección, G. PISARELLO, Los derechos..., cit., pp. 37 y ss. 
existen) entre el fundamento de los derechos liberales y el propio de los derechos sociales.

2) Estado social. El principio del Estado social no ha arrojado frutos significativos en nuestra doctrina ni en nuestra jurisprudencia. Nuevamente, debemos ser aquí cautelosos: se trata de convencer a los aplicadores del Derecho, no de realizar una construcción brillante y novedosa que nadie entienda ni comparta. A nuestro juicio, la mayor virtualidad del principio residiría en su colocación al lado y al mismo nivel que la democracia y el Estado de Derecho. No se ha reparado suficientemente en este punto, ni siquiera en los intentos realizados de ponderación ${ }^{19}$. La tesis mayoritaria, machaconamente repetida, de la prioridad de la decisión del Parlamento sobre el control judicial en materia social, aun aceptando el concepto de democracia del que parte, olvida que el Estado social vale tanto como la democracia y que esta debe ceder (triunfos frente a la mayoría, coto vedado y otras fórmulas sólo aplicadas, ideológicamente, a los derechos de libertad) ante los requerimientos propios del Estado social ${ }^{20}$.

3) Igualdad. Seguramente el principio más útil (por mejor asentado doctrinalmente) para la interpretación progresiva de los derechos sociales sea la igualdad, que conviene analizar de forma conjunta (como valor, principio y derecho), desde una construcción unitaria. A nuestro juicio, la distinción radical entre igualdad formal/jurídica - igualdad material/ fáctica es errónea ${ }^{21}$. La igualdad (desde luego como principio y mandato, y a veces también como derecho) incluye un deber de diferenciación o trato diferenciado; esto es, si la norma consagra, incluso por omisión, una desigualdad de hecho, esa norma es inconstitucional.

19 Calificados con acierto de ideológicos, «en el sentido marxiano del término» por M. A. APARICIO PÉrEZ, «Modelo constitucional de Estado y realidad política», en P. Andrés Ibáñez (ed.), Corrupción y Estado de Derecho. El papel de la jurisdicción, Trotta, Madrid, 1996, p. 33.

${ }^{20}$ No es esta, desde luego, la opinión dominante, que realiza una lectura descompensada de los tres principios, mediante la cual el Estado social, al subordinarse a los otros dos, prácticamente desaparece como norma jurídica. Denunciando esta lectura sesgada de la CE, p. ej., además del trabajo de APARICIO recién citado, en el mismo volumen, M. A. GARCíA HERRERA, «Poder judicial y Estado social. Legalidad y resistencia constitucional», esp. pp. 65-69 o C. DE CABO, Teoría..., cit., esp. p. 53. Un buen ejemplo del sentir dominante es J. M. RodríGUEZ DE SANTIAGO, La administración del Estado social, Marcial Pons, Madrid, 2007, donde, tras aludirse retóricamente a la igualdad entre los tres principios se acaba defendiendo un modelo social sin Estado y, desde luego, sin Constitución, donde el Derecho administrativo tiene la primera y la última palabra.

${ }^{21}$ Modélica al respecto la STC 253/2004. Para un impecable planteamiento teórico, L. Villacorta Mancebo, Principio de igualdad y Estado social, Universidad de Cantabria, Santander, 2006, esp. pp. 93 y ss. 


\section{LOS DERECHOS SOCIALES COMO DERECHOS FUNDAMENTALES}

La Filosofía del Derecho aporta elementos esenciales para comprender y, en su caso, construir, el fundamento de los derechos sociales. Detrás de nuestras opciones interpretativas como juristas (un oficio sin duda más modesto que el de filósofo) se encuentran precomprensiones, las cuales deben explicitarse y fundarse (en la medida de lo posible) en los principios constitucionales nucleares. Los filósofos deberían construir tesis sólidas (con base empírica, que a veces se echa en falta) que pudieran hallar correspondencia en las categorías de valor presentes en la Constitución formal y que ofrecieran pistas para una construcción dogmática más firme de los derechos sociales en concreto; al respecto, la dignidad (en su conexión con la libertad real) y la igualdad resultan ser los candidatos más idóneos (no tanto las necesidades, que como tales no suelen aparecer en los textos constitucionales). Por otra parte, la propuesta de fundamentación filosófica de los derechos sociales no debería olvidar los avances logrados por el Derecho internacional, pues Filosofía y Derecho internacional se complementan (ambas disciplinas tratan de los derechos humanos, en el sentido amplio del término $)^{22}$.

Los derechos sociales de los que hablamos son derechos fundamentales sociales de prestación (aunque ya venimos hablando de derechos sociales a secas, por abreviar): derechos (subjetivos), por representar intereses individuales judicialmente exigibles; fundamentales, por estar reconocidos en la Constitución formal y gozar de las garantías típicas de esta (vinculación del legislador y tutela judi$\left.\mathrm{cial}^{23}\right)$; sociales, por corresponder al catálogo típico de esta categoría histórica (cuya plasmación más aceptada se encuentra en los arts. 6 a 15 PIDESC); de prestación, por ser este el rasgo más característico de su estructura (con las matizaciones que después se harán), lo que excluye a las libertades sindical y de huelga.

De entrada, hay que precisar el catálogo de los derechos sociales (¿cuáles son?). Desde luego, forman parte del catálogo los definidos como derechos en la Constitución, así como los permitidos por las cláusulas de apertura: el Derecho internacional y la dignidad de la persona ${ }^{24}$.

${ }^{22}$ He intentado demostrar esta conexión en G. EsCOBAR RoCA, Introducción..., cit., pp. 16 y ss.

${ }^{23} \mathrm{El}$ art. 53.3 CE no ha sido entendido correctamente. Para una primera interpretación alternativa, p. ej., G. EsCOBAR ROCA, La ordenación constitucional del medio ambiente, Dykinson, Madrid, 1995, pp. 71 y ss.

${ }^{24}$ Ibidem, esp. pp. 35-36. 
Todos los derechos sociales son, en cierto modo, de estructura compleja: contienen, ante todo, obligaciones de acción (de prestación de servicios, bienes o cantidades de dinero, económicamente cuantificables todas ellas y accesibles en el mercado) pero también, de forma complementaria y accesoria, obligaciones de abstención (p. ej., no atentar contra la salud, no desahuciar de una vivienda). Estas segundas son menos importantes y apenas plantean problemas dogmáticos (basta aplicar la doctrina general de los derechos de libertad). En lo sucesivo pensaremos sobre todo en la estructura típica de los derechos sociales y en su contenido característico, esto es, las prestaciones.

La relación entre libertades y prestaciones, dentro de un solo derecho, no acaba aquí: si son derechos, su ejercicio, por definición, es libre. Ello trae como consecuencia un problema de los derechos sociales (por cuanto puede crear un efecto disuasorio a su ejercicio) seguramente inevitable: como regla general, hay que solicitar que se cumplan (acudir a un hospital, presentarse a una convocatoria de ayudas a la vivienda), no esperar a que se cumplan.

El contenido de los derechos sociales consiste entonces, sobre todo, en prestaciones (o, más exactamente, en obligaciones de prestar). Las prestaciones pueden ser muchas o pocas (p. ej., desde una vivienda para cada habitante, en propiedad y con todas las comodidades, hasta una sencilla habitación compartida en un albergue comunitario). Ni podemos pedir lo imposible a la Constitución ni podemos renunciar a fijar contenidos. No hay que definirlo todo sino sólo el contenido mínimo o constitucional de un derecho, esto es, exigible al legislador. Al resto, que no es prioritario definir, podemos llamarlo contenido adicional. La determinación del contenido mínimo o constitucional de los derechos sociales implica una doble operación: definición del objeto o bien protegido (qué es la educación, la salud o la vivienda) y determinación de los medios indispensables para su protección. Esto es, la determinación del contenido implica concretar fines y medios, pero sobre todo lo primero. Lo segundo es algo más abierto (normalmente son posibles diversos medios o formas de alcanzar un fin) a la discrecionalidad del legislador. Quizás sea preferible centrarse (dogmáticamente) en determinar el objeto del derecho y no concretar demasiado las obligaciones de los poderes públicos al respecto, operando con ellas de modo inverso: analizando críticamente la ley (si bien la crítica presupone una implícita concepción de las obligaciones constitucionales).

Creo preferible ser realistas en la determinación del contenido mínimo: aunque la ponderación no juegue ahora, sino después, no conviene pedir demasiado a la Constitución. Aquí la fundamentación del derecho (que conecta con la interpretación finalista) debe ofrecernos las claves, sin olvidar un fuerte componente empírico (indicadores internacionalmente aceptados, necesidades). 
El cómo determinar el contenido mínimo de los derechos sociales está muy relacionado con el quién. Se impone aquí el diálogo colectivo (un cierto reconocimiento a las teorías procedimentales de los derechos, a lo Habermas). Advertimos, sin embargo, de un peligro: otorgar todo el protagonismo al legislador. La idea apuntada bien por Nino (el Parlamento como lugar adecuado para definir los derechos) sólo sería aceptable si las condiciones ideales de la democracia (el Parlamento como foro abierto) se realizaran en la práctica.

En relación con los titulares de los derechos debe señalarse que las prestaciones que conforman el contenido del derecho deben ser asequibles a todos, lo que no quiere decir gratuitas.

Salvo que el constituyente lo excluya expresamente, los derechos sociales pertenecen a todas las personas, dada su directa derivación de la dignidad. Por lo mismo, no pertenecen a las personas jurídicas. Otra cosa es que determinadas personas jurídicas tengan derecho a prestaciones constitucionales, pero no como titulares de derechos sino como una forma de garantizar los derechos de personas físicas.

El principio de igualdad se ha desvelado como mecanismo idóneo para extender la titularidad de los derechos sociales a personas concretas o a colectivos excluidos de las prestaciones ${ }^{25}$.

Por lo que se refiere a los obligados por los derechos, es un lugar común afirmar que las prestaciones que integran el contenido de los derechos sociales deben ser realizadas por el Estado, y así es en la mayor parte de los casos: primero por el legislador (a quien podemos dirigirnos en casos claros de omisión) y después (y más habitualmente) por la Administración. A los tribunales sólo debe acudirse cuando el derecho no se ha cumplido: no les exigimos el cumplimiento del derecho sino su garantía.

Los derechos sociales vinculan de forma indirecta o mediata a los particulares: el legislador puede, sin renunciar al control y supervisión última (con técnicas propias del servicio público o similares), delegar en aquellos el otorgamiento de prestaciones. Así sucede por ejemplo en España con la asistencia letrada y, parcialmente, con la educación.

Una de las cuestiones clave a decidir es si el esquema típico de análisis de las intervenciones sobre los derechos de defensa puede aplicarse o no a los derechos sociales. Como ya he señalado, la aplicación de este esquema reforzaría la unidad del sistema de los derechos y, dada su relativa consolidación en la práctica y dogmática jurídicas, favorecería la expansión de los derechos sociales.

${ }_{25}$ Por todos. V. Abramovich y C. CourTis, Los derechos sociales como derechos exigibles, Trotta, Madrid, 2002, pp. 169 y ss. 
El supuesto más desarrollado por la doctrina (apenas por la jurisprudencia) y que podría trasladarse, mutatis mutandis, a otros ámbitos, es el de los actos y normas regresivas. El modelo de análisis sería el siguiente: un acto o una norma que por su contenido o consecuencias implica rebajar el nivel anterior de prestaciones es una intervención sobre el derecho que por tanto debe ser justificada mediante la fórmula típica de los derechos de libertad (no vulneración del contenido esencial, fundamento constitucional —límite- y proporcionalidad). El segundo requisito exige alguna explicación: valen sobre todo los límites directos y materiales y sólo excepcionalmente los indirectos y formales ${ }^{26}$. En estos casos quien interviene asume la carga de una detallada argumentación. Por ejemplo, hay que evitar el recurso indiscriminado al argumento presupuestario (la reserva de lo económicamente posible): si se utiliza (tampoco parece razonable excluirlo del todo), habrá de explicarse muy bien por qué no hay fondos y dónde se destinan los que hay.

La cuestión que queda en pie y que hay que resolver es el control de las omisiones absolutas (ámbito en el cual el esquema anterior parece que no sirve, pues no hay intervención) con el problema añadido de su falta de previsión expresa en nuestro Derecho procesal constitucional. En realidad, en el ámbito legislativo tenemos un pseudoproblema (suele haber leyes sobre todos los derechos sociales y por tanto no hay omisión absoluta). Con ello, las dificultades se diluyen (pero no desaparecen del todo) también en el ámbito administrativo, pues las omisiones absolutas de la Administración pueden ser controladas con la técnica, ya bastante asentada, de los principios de legalidad y jerarquía normativa.

\section{EL DERECHO FUNDAMENTAL A LA PROTECCIÓN DE LA SALUD: FUNDAMENTO, CONTENIDO Y LÍMITES ${ }^{27}$}

\subsection{Fuentes}

El derecho fundamental a la protección de la salud (en adelante, DPS) surge por vez primera en España con la Constitución de 1978. Las previsiones so-

26 Vid. al respecto los diversos trabajos contenidos en C. CourTis (comp.), Ni un paso atrás. La prohibición de regresividad en materia de derechos sociales, Ediciones del Puerto, Buenos Aires, 2006. La tendencia que va imponiéndose es considerar como legítima la regresividad sólo cuando afecta al contenido adicional del derecho y siempre que dicha afectación se encuentre justificada, correspondiendo la carga de la prueba al poder público.

27 Sólo para respetar los límites de extensión marcados por la Revista de Derecho político, dejamos fuera de esta síntesis el estudio de los titulares y obligados del derecho. 
bre el tema contenidas en la Constitución de la II República (arts. 43.6 y 46.2) eran meros mandatos a los poderes públicos, que quedan claramente superados por la CE.

El DPS es un derecho fundamental porque existe una norma constitucional de reconocimiento del mismo (art. 43.1). El artículo 53.3 CE no es obstáculo para ello, o al menos no contiene un obstáculo distinto al propio de los derechos del capítulo segundo (necesidad de plantear la cuestión de inconstitucionalidad frente a las leyes vulneradoras).

$\mathrm{La}$ CE contiene diversas disposiciones relacionadas con la salud; unas sirven para reforzar, por conexión, la fundamentalidad del DPS (art. 15) ${ }^{28}$, otras para delimitar negativamente su contenido (arts. 41 y 45) y otras para imponer determinados contenidos mínimos del derecho (arts. 40.2 y 51) o acciones afirmativas a favor de determinados colectivos (arts. 49 y 50). En cuanto a la delimitación negativa, considero que la $\mathrm{CE}$ impone un modelo de protección de la salud desvinculado del modelo tradicional de la Seguridad Social (cotización como requisito para la asistencia), que es precisamente la solución que ha terminado imponiéndose por vía legislativa.

Dejando de lado las Sentencias que integran la salud en el contenido del artículo $15 \mathrm{CE}$, la escasa doctrina del Tribunal Constitucional que se ha ocupado de cuestiones sanitarias se refiere a la distribución de competencias entre el Estado y las Comunidades Autónomas. En estas decisiones se apunta a favor del deber estatal de mantenimiento de la igualdad básica en el disfrute del DPS entre todos los ciudadanos, con mención expresa al artículo 149.1.1 a $\mathrm{CE}^{29}$.

Entre la normativa de rango cuasiconstitucional (art. 10.2 CE) destaca con claridad el artículo 12 PIDESC y su interpretación en la Observación General del Comité de Derechos Económicos, Sociales y Culturales núm. 14, sobre el derecho al disfrute del más alto nivel posible de salud (en adelante, OG 14), que puede considerarse fuente indirecta del DPS, y, entre la normativa comunitaria, la jurisprudencia del TJCE sobre la obligación de asistencia sanitaria a los ciudadanos comunitarios ${ }^{30}$.

28 Últimamente, SSTC 62/2007 y 160/2007.

29 SSTC 32/1983, 42/1983, 87/1985, 111/1986 y 98/2004, esta última avalando implícitamente (con cinco votos particulares) la tesis de la distinción entre contenido mínimo (indisponible por las Comunidades Autónomas) y adicional (disponible) de los derechos fundamentales sociales, a la que después se hará referencia.

30 SSTJCE Kohll, de 28 de abril de 1998, Smits y Peerbooms, de 12 de julio de 2001, etc. Para un análisis en profundidad, T. K. HerveY y J. V. Mc Hale, Health Law and the European Union, Cambridge University Press, Cambridge, 2004, pp. 109 y ss. 
No existen omisiones legislativas absolutas. El DPS ha sido desarrollado, sobre todo, por tres leyes: la Ley General de Sanidad (LGS), la Ley de Cohesión y Calidad del Sistema Nacional de Salud (LCC) y la Ley de Autonomía del Paciente (LAP). Pese a algunas incorrecciones y ambigüedades del legislador, de este conjunto legislativo (interpretado conforme a la CE) puede deducirse que el DPS es un derecho subjetivo judicialmente exigible, sobre todo, frente a la Administración.

\subsection{Concepto}

La definición de la Organización Mundial de la Salud («completo estado de bienestar físico, mental y social») no resulta adecuada para construir un concepto constitucional de salud. Parece más correcto partir de una acepción más restringida, identificando así la salud con la ausencia de enfermedades o, como dice el legislador español, con la ausencia de «enfermedades, [la] conservación de la esperanza de vida, [...] y [la] eliminación o disminución del dolor y el sufrimiento» (art. 20.3 LCC). Es evidente que la determinación, por ejemplo, de qué es una enfermedad, en qué condiciones debe mantenerse una vida humana o qué cabe entender por dolor y sufrimiento está en dependencia de variables éticas, sociales y científicas. Desde la perspectiva constitucional, debe examinarse si la salud perseguida por el ordenamiento resulta coherente con dichas variables y no se somete a pautas de otra naturaleza, como las financieras (si bien la situación económica de un país puede incidir, indirectamente, sobre la concepción de la salud que tiene una sociedad).

Más importante que definir la salud es definir la «protección de la salud» impuesta por la CE. No parece correcta la propuesta de la OG 14 de incluir en la definición los llamados condicionantes de la salud (ambiente sano, trabajo seguro, agua potable, buena alimentación y vivienda digna); ello no quiere decir que dichos condicionantes carezcan de trascendencia sino que encuentran mejor acomodo en otras normas constitucionales.

La protección de la salud es una norma de carácter finalista. Sin embargo, no puede exigirse la salud como tal (algo muchas veces imposible para la acción humana) sino más bien que se realicen acciones en su favor (obligación de medios), aunque en ocasiones pueden exigirse también resultados; piénsese sobre todo en los casos de enfermedades claramente susceptibles de curación ${ }^{31}$.

31 De esta forma, no podemos aceptar, al menos en términos absolutos, la doctrina jurisprudencial según la cual las obligaciones sanitarias son siempre obligaciones de medios. 
La salud como bien jurídico-constitucional es única, pues en última instancia mira siempre hacia el interés de personas concretas. En definitiva, las expresiones «salud» del artículo 43.1 CE y «salud pública» del artículo 43.2 no aluden a objetos distintos sino a uno solo ${ }^{32}$, que puede protegerse de dos maneras distintas:

a) La protección de la salud individual abarca el conjunto de acciones dirigidas a tutelar la salud (esto es, conservar la vida, favorecer la autonomía y eliminar o paliar la enfermedad, el dolor y el sufrimiento) de personas concretas en casos concretos, normalmente a solicitud de estas. Los dos componentes típicos del contenido del derecho, entendido en este sentido, son la asistencia sanitaria y, como prolongación de esta, el derecho al medicamento.

b) La protección de la salud pública (también llamada colectiva) abarca el conjunto de acciones (en su mayoría preventivas), dirigidas igualmente a tutelar la salud, en el sentido antes indicado, pero al margen o con independencia de la situación concreta de personas concretas. La determinación de las acciones que integran esta forma de protección es más difusa que en el caso anterior, pero hoy día la normativa internacional y los antecedentes históricos (el Estado se preocupó antes de proteger la salud colectiva - policía sanitaria- que la salud individual —asistencia sanitaria-) permiten dibujar un conjunto bastante diferenciado y consolidado de actuaciones sobre las que difícilmente cabría marcha atrás, conformando así una suerte de garantía institucional de la salud pública, ahora consolidada por obra del artículo 43.2 CE.

Como regla general, la protección de la salud individual configura el contenido del derecho fundamental subjetivo y la protección de la salud pública el carácter meramente objetivo de dicho derecho fundamental. Sin embargo, hay también algunas excepciones o supuestos de intersección (acciones en defensa de la salud pública que forman parte del contenido del DPS estrictamente considerado).

\subsection{Fundamento}

La existencia de un derecho humano a la salud es clara para el Derecho internacional (vinculante para el intérprete, recordemos, ex art. 10.2 CE) y para la implícita concepción moral de nuestro constituyente. Dejado de lado el princi-

32 Así, C. Cierco SeIrA, Administración pública y salud colectiva, Comares, Granada, 2006, p. 8. 
pio de dignidad, que normalmente se presenta asociado a otros ${ }^{33}$, la faceta prestacional del derecho ${ }^{34}$ puede fundamentarse doblemente:

a) El valor de la libertad (art. 1.1 CE) o, si se quiere, el «libre desarrollo de la personalidad» (art. 10.1), ofrece un buen fundamento del DPS; las teorías morales más relevantes, a saber, las que defienden un mínimo decente en materia sani$\operatorname{taria}^{35}$ y las herederas de la tesis de SEN sobre las capacidades ${ }^{36}$, coinciden en dotar de importancia al derecho en la medida en que resulta necesario para poder ejercer realmente la libertad (art. 9.2). Así, dentro del contenido del derecho habrá de incluirse, al menos, el aseguramiento de la salud necesaria para poder ejercer los derechos de libertad expresamente reconocidos en la CE: desarrollar ideas y exponerlas (arts. 16 y 20), desplazarse (art. 19) o realizar una vida social y económica activa (arts. 21, 22, 23, 35 y 38). Pese a las afirmaciones del Preámbulo y del artículo 45.2, la CE no reconoce un derecho al bienestar o a la calidad de vida, pero ambos bienes pueden conectarse con el artículo 10.1, a fin de justificar los cuidados a la salud en los casos no cubiertos por específicos derechos de libertad.

b) El valor o principio de igualdad, por su parte, tiene menos fuerza, al menos de manera autónoma (complementa eficazmente al valor de la libertad, que debe ser efectiva o libertad para todos), para fundamentar el DPS. La igualdad sirve, sobre todo, para extender la titularidad del derecho o de alguno de sus elementos: un derecho que sólo beneficia a una minoría no es un derecho fundamental, consideración esta que se deriva de la misma naturaleza de esta categoría pero que queda más clara si atendemos a la conexión del derecho con el valor o principio de igualdad. En todo caso, la igualdad impide diferencias de trato injustificadas en el disfrute del DPS, y ello tanto en un sentido jurídico como fáctico. En primer lugar, habrá que examinar si las normas que excluyen a los extranjeros de la titularidad del derecho y las que establecen diferencias en el

33 Sea como fuere, no cabe descartar un uso residual del principio de dignidad, en aquellos casos en los cuales el principio de libertad resulte insuficiente para justificar prestaciones moralmente exigidas por la comunidad, especialmente cuando está en riesgo la vida de las personas. La dignidad es un principio jurídico que involucra obligaciones de terceros y bien puede considerarse un trato indigno, necesitado por tanto de eliminación mediante acciones positivas, dejar sin asistencia sanitaria a personas necesitadas de cuidado, más cuando sin dicho cuidado una persona podría fallecer.

${ }^{34}$ La faceta defensiva del derecho puede fundamentarse más fácilmente, siguiendo los parámetros clásicos de la justificación liberal.

35 Por todos, N. Daniels, Just Health Care, Cambridge University Press, Cambridge, 1985.

36 P. ej., G. Vidiella, El derecho a la salud, Eudeba, Buenos Aires, 2000 o J. P. Ruger, «Toward a Theory of a Right to Health: Capability and Incompletely Theorized Agreements», Yale Law \& Humanities, vol. 18, 2006. 
contenido del derecho según el lugar de residencia de su titular son constitucionales. En segundo lugar, deberá atenderse a las condiciones reales de disfrute del derecho, el cual tiene por objeto principal, como sabemos, proteger frente a la enfermedad, sin que quepa establecer diferencias por razón de la misma. Es más: en la lógica del derecho está proteger antes las enfermedades más importantes, esto es, atender primero a quien se encuentra en peor situación. De esta forma, el derecho tiene un componente natural, un mandato implícito de acción afirmativa ${ }^{37}$, y así se señala parcialmente en la propia Constitución (p. ej., arts. 49 y 50) y se recuerda con reiteración en la OG 14, entre muchos otros documentos internacionales.

\subsection{Estructura y contenido}

El DPS puede considerarse, con matizaciones, un derecho de estructura compleja: tiene, en cierto modo, elementos que encajan en las cuatro estructuras básicas de un derecho ${ }^{38}$, pero entre ellas domina claramente el elemento prestacional. Por ello, resulta correcto calificar el DPS como un derecho social.

Como hemos adelantado, la normativa vigente configura un auténtico derecho subjetivo, esto es, judicialmente exigible por los particulares ${ }^{39}$; siendo esto así,

37 Si la pobreza es la primera causa de las diferencias en el estado de salud de las personas (por todos, C. POND y J. POPAY, «Poverty, economic inequality and health», en Dilemmas in health care, Open University Press, orwich, 2. ${ }^{\text {e }}$ ed., 1996, pp. 184 y ss.), la misma existencia de un DPS de titularidad universal lleva consigo una carga antidiscriminatoria evidente.

38 G. EsCOBAR Roca, Introducción..., cit., pp. 54 y ss.

39 Así, los dos primeros párrafos del artículo 1 LGS hablan, literalmente, de «derecho a la protección de la salud» y el párrafo cuarto del mismo precepto confirma plenamente que nos hallamos ante un derecho subjetivo, al afirmar que, para su ejercicio (más exactamente, para su cumplimiento primero y para su garantía después), sus titulares «están legitimados, tanto en la vía administrativa como jurisdiccional». La LCC, que se mueve en una lógica algo distinta, no contiene una fórmula general de reconocimiento del derecho o de derechos asociados al mismo, sino que se preocupa tan sólo de reconocer (al menos, expresamente) aquellos derechos que considera necesarios para la cohesión del SNS, lo que guarda relación, sobre todo, con el derecho a la igualdad (art. 4 LCC). Sin embargo, para el DPS la LCC resulta quizás más importante que la propia LGS, por cuanto concreta con una precisión antes inexistente a nivel legal el contenido de las prestaciones que cabe exigir como parte del SNS. Inicialmente, en el artículo 3.1 se hace una alusión genérica a los «derechos a la protección de la salud y a la atención sanitaria» y luego los artículos 7 a 19 detallan las prestaciones del SNS, sin que llegue a realizarse una conexión entre ambos tipos de preceptos. A nuestro juicio, de la interpretación sistemática (del conjunto de la LCC y de esta con la LGS) se deduce que las prestaciones del SNS forman parte del contenido del derecho fundamental subjetivo a la salud (esto es, pueden exigirse en última instancia ante los tribunales), salvo que por su contenido no quepa establecer una relación clara con la salud individual de personas concretas. 
la mención al artículo 53.3 CE resultaría ya del todo superflua, incluso para quienes defienden la inexistencia de auténticos derechos en el capítulo tercero.

La determinación del contenido del DPS corresponde, como es habitual, primeramente al legislador, con la colaboración del poder reglamentario, que incluye aquí normas muy peculiares ${ }^{40}$, y subsidiariamente, en los casos particulares, a la jurisprudencia y a la propia Administración, incluyendo, en última instancia, a los profesionales sanitarios. El margen de indeterminación de las prestaciones que conforman el contenido del derecho es relativamente abierto; de ahí la importancia de la deliberación pública en este ámbito (algo exigido, por otra parte, por el art. 28 del Convenio de Oviedo) y de la participación social en la toma de decisiones correspondiente.

En la determinación del contenido del DPS hay tres cuestiones generales a resolver, que remiten a su vez a tres biparticiones de dicho contenido:

a) ¿Cuál es el contenido mínimo del derecho, indisponible por el legislador? De no encontrarse dicho contenido mínimo reconocido en la ley, existiría inconstitucionalidad por omisión. Este contenido está integrado por las acciones necesarias para proteger el objeto del derecho (la salud) constitucionalmente definido, de conformidad con los valores, también constitucionales, que le sirven de fundamento. Las dificultades de precisar este contenido (de separar entre contenido mínimo y el contenido adicional) son obvias, de ahí que, en búsqueda del consenso, podamos asumir la determinación que realiza la OG 14, la cual, dejando fuera los llamados condicionantes de la salud, incluye obligaciones estatales en una serie determinada de materias.

b) ¿Pueden existir contenidos diferentes del derecho, según el lugar de residencia? De conformidad con la jurisprudencia constitucional, la existencia de contenidos adicionales distintos resulta legítima ${ }^{41}$. Como regla general, si las diferencias (jurídicas y fácticas) entre Comunidades Autónomas afectan al contenido mínimo del DPS son inconstitucionales y si afectan al contenido adicional son constitucionales.

${ }^{40}$ Nos referimos a los protocolos o guías de actuación, cuyo carácter normativo se destaca en el art. 4.7 b) LOPS y, sobre todo, a lo largo y ancho del importante Real Decreto 1030/2006, de Cartera de Servicios Comunes (en adelante, RDCSC).

${ }^{41}$ Esto conlleva que pueda negarse un determinado tratamiento (o negar su gratuidad) a un paciente que no tenga establecida su residencia en una Comunidad Autónoma que haya decidido ir más allá del contenido adicional del derecho. Esta diferencia de trato entre residentes y no residentes parece objetiva y razonable (STC 98/2004) y no creemos aplicable el razonamiento de la jurisprudencia estadounidense según el cual la diferencia de trato vulneraría «el derecho fundamental a viajar» (sic). 
c) ¿Todos los contenidos del derecho son exigibles como derecho subjetivo? Existe una parte del derecho fundamental que es meramente objetiva ${ }^{42}$ : sirve a los mismos intereses (la protección de la salud, que en última instancia es siempre salud individual) pero no siempre puede ser exigida ante los tribunales; desde otra perspectiva, puede afirmarse que forma más bien parte de las garantías (objetivas) del derecho y no tanto de su contenido. Así sucede con la parte sustancial de la política de salud pública ${ }^{43}$. Esta política, que cabe definir como aquella destinada a la prevención y control de enfermedades al margen de la asistencia sanitaria concreta $^{44}$, forma parte de las prioridades de la LGS y de la LCC y se concreta en un amplio y variado conjunto de obligaciones de las Administraciones públicas, cuya vinculación jurídica resulta sin embargo bastante relativa ${ }^{45}$. No hay que olvidar, sin embargo, el valor añadido de esta normativa (desarrollo, en definitiva, del art. 43.2 CE) como límite o justificación de las intervenciones sobre derechos fundamentales (incluyendo el mismo DPS, en su faceta individual), lo que en última instancia redunda en beneficio de la salud individual, habida cuenta de que, como sabemos, el bien jurídico protegido es el mismo.

En primer lugar, el DPS es un derecho reaccional. Frente a los ataques directos a la salud individual, normalmente procedentes de particulares, el afectado dispone, según los casos, de una acción administrativa, civil o penal (o de varias a la vez) para obtener una satisfacción. En estas situaciones, el deber estatal de reparación del daño no es discrecional sino que dimana del propio DPS. Examinada la legislación española, se comprueba que existe protección suficiente del DPS como derecho reaccional.

42 Detrás de esta tesis se encuentra seguramente la imposibilidad fáctica de dar satisfacción efectiva a todos los intereses relacionados con la salud.

${ }^{43} \mathrm{La}$ LCC incluye algunas acciones en materia de salud pública que creemos forman parte del derecho subjetivo a la salud (sobre todo, art. 12.2 c) y d), desarrollado por los apartados 3 y 4 del Anexo II del RDCSC). La conversión de obligaciones administrativas en contenido del derecho subjetivo está más clara en algunas leyes autonómicas.

${ }^{44}$ Hacemos esta precisión conceptual, pues la legislación utiliza con frecuencia un concepto muy amplio de salud pública, que prácticamente la identifica con la salud sin más. Por otra parte, uno de las finalidades principales de la LGS, no conseguida del todo, fue integrar las medidas preventivas en el ámbito de la asistencia sanitaria individual (p. ej., arts. 12.1 y 13.1 LCC), en cuyo caso nos encontraríamos fuera, a nuestro entender, del concepto típico de salud pública.

45 P. ej., ninguna de las carencias de la sanidad española, que habitualmente se critican (p. ej., V. NAVARRO, «La sanidad en España», en La situación social en España, Biblioteca Nueva, Madrid, 2005, pp. 455-458) sería fácilmente superable mediante la mera invocación de los mandatos constitucionales aplicables, al margen de la lógica de los derechos subjetivos. Desde luego, no cabe descartar (y resulta recomendable como estrategia procesal) la exigencia ante los tribunales de obligaciones legales de la Administración, por la vía del art. 43.1 CE. 
En segundo lugar, el DPS es un derecho de libertad, esto es, la salud no se configura constitucionalmente como un deber (aunque la ley puede prever deberes sanitarios para proteger, entre otras cosas, la salud colectiva) sino como una prestación que puede obtenerse si se solicita y sólo si se solicita. Para garantizar el adecuado ejercicio de la libertad, la LAP prevé una serie de obligaciones de la Administración, básicamente de suministro de información, que pueden considerase integradas en el contenido del DPS. Los tratamientos sanitarios obligatorios implican una intervención sobre la faceta defensiva del DPS que debe ser justificada en la necesidad de proteger otros bienes constitucionales, debiendo respetarse en todo caso el principio de proporcionalidad.

En tercer y fundamental lugar, el DPS es un derecho de prestación (en sentido amplio), consistente, en síntesis (este trabajo no puede detenerse en todas las cuestiones abordadas en el capítulo que aquí se resume, como el derecho al medicamento), en la asistencia sanitaria en caso de enfermedad, dolor o sufrimiento.

Los elementos más importantes del derecho a la asistencia sanitaria son cuatro $^{46}$ :

a) Disponibilidad. Según el apartado 12 de la OG 14, el Estado debe contar con un «número suficiente de establecimientos, bienes y servicios públicos de salud y centros de atención de la salud», lo que entre otras cosas incluye "hospitales y clínicas». En España tradicionalmente se sigue el modelo de provisión directa de servicios sanitarios, tendencia que consolidan los artículos 66.1 LGS y 9 LCC.

La sanidad no puede ser considerada un servicio público en sentido formal pero sí en sentido material ${ }^{47}$ : ni existe monopolio público sobre el sector ni se precisa la apertura de un concurso público (aunque sí una autorización previa, art. 29.1 LGS) para la puesta en marcha de un centro sanitario privado (lo que se considera ejercicio de la libertad de empresa, arts. 88-89 LGS); sin embargo, la creación y mantenimiento de una red pública sanitaria viene impuesta por la $\mathrm{CE}$, y así lo corrobora, como hemos visto, la legislación vigente.

La sanidad pública española se configura desde la LGS como una organización única, denominada Sistema Nacional de Salud (SNS), que integra todas las estructuras y medios públicos (actualmente de titularidad autonómica) al servicio de la salud. A grandes rasgos, puede considerarse que el Sistema cuenta hoy con capacidad suficiente para atender a la totalidad de la población espa-

${ }^{46}$ Dejamos fuera los elementos de accesibilidad geográfica, integridad y continuidad.

47 En esta línea, ya antes de la discusión en España sobre el «nuevo servicio público», J. M. FERnÁNDEZ PASTRANA, El servicio público de la sanidad: el marco constitucional, Civitas, Madrid, 1984 , pp. 26 y ss. 
ñola. Las carencias del sistema pueden considerarse excepcionales y casi inevitables ${ }^{48} \mathrm{y}$, salvo lo que después se dirá sobre el reintegro de gastos sanitarios y sobre las listas de espera, no puede hablarse de inconstitucionalidad estructural o normativa por vulneración del elemento de la disponibilidad.

No cabe liberalizar el sector (pues, estrictamente, ya lo está) pero sí privatizar centros públicos y hacer un uso más frecuente de las fórmulas de adscripción de centros sanitarios privados al SNS. Una eventual política pública de tal signo, en principio, no parece prohibida por la $\mathrm{CE}^{49}$, pero implica indudables riesgos para la efectividad del DPS. Aunque la normativa vigente introduce algunas cautelas, es evidente que las mismas, cuyo diseño resulta en todo caso incompleto, van a ser siempre insuficientes para garantizar que la asistencia se presta en igualdad de condiciones con los centros públicos. Además de los controles posteriores, que siempre caben, creemos que sería aconsejable, al menos, en línea con lo propuesto implícitamente por el apartado 35 de la OG 14 y expresamente por la Federación Iberoamericana de Ombudsman ${ }^{50}$, la introducción de una exigencia legal de garantía previa de la efectividad del derecho en los centros sanitarios privados que quieran adscribirse al SNS.

Un elemento importante, ya anunciado, del componente del derecho que ahora analizamos es la posibilidad de acudir a un centro sanitario privado cuando no resulta posible hacerlo a uno público (estrictamente, del SNS), con derecho al posterior reintegro de los gastos correspondientes. De 1967 a 1986 el reintegro se producía en dos supuestos: denegación injustificada de asistencia sanitaria (lo que era interpretado por la jurisprudencia en un sentido muy favorable al DPS) y «asistencia urgente de carácter vital» (art. 18 del Decreto 2766/1967). El artículo 17 LGS, todavía vigente, optó por una fórmula de exclusión prácticamente total del reintegro, lo cual fue matizado por el artículo 5.3 del Real Decreto 63/1995 (hoy art. 4.3 RDCSC) y actualmente por el ya citado artículo 9 LCC. Este último precepto parece permitir un único supuesto de reintegro (las «situaciones de riesgo vital», que es algo más amplio que la urgencia pero menos que la denegación injustificada de asistencia), interpretación que corrobora el artículo 4.3 RDCSC. De esta forma, se produce un retroceso con re-

48 J. Pemán Gavín, Asistencia sanitaria y Sistema Nacional de Salud, Comares, Granada, 2005, p. 105 llega a hablar de un cierto déficit «estructural» del sistema de provisión pública, que no se da en el sistema de provisión privada con financiación pública por acto médico.

49 Tesis unánime en la doctrina, incluso desde las posiciones más avanzadas. Vid., p. ej., RoDríguez-Piñero y Del Rey Guanter, «Informe español», en A. Marzal (ed.), Protección de la salud y Derecho social, Bosch, Barcelona, 1999, pp. 110-112.

${ }^{50}$ Recomendación 5, en FEDERACIÓN IBEROAMERICANA DE OMBUDSMAN, $I V$ Informe sobre Derechos Humanos: Protección de la salud, Trama, Madrid, 2006, p. 554. 
lación a la etapa de la vigencia del Decreto 2766/1967, pues la «denegación injustificada» era interpretada abarcando los casos de recurso a la sanidad privada tras un error de diagnóstico en la pública ${ }^{51}$, falta de medios ${ }^{52}$ o espera prolon$\operatorname{gada}^{53}$, posibilidades que ahora cierra la normativa vigente ${ }^{54}$. A nuestro juicio, se dan aquí los requisitos de regresión vulneradora del derecho fundamental, y precisamente por ello, consideramos que los artículos 17 LGS y 9 LCC son inconstitucionales, ya que, sin razón aparente, se elimina una parte del contenido del DPS antes existente. La valoración conjunta del nivel actual de protección no permite salvar la constitucionalidad del retroceso ${ }^{55}$.

Llegados a este punto, debe llamarse la atención sobre una idea que ya fue anunciada con carácter general: ninguno de los elementos prestacionales del derecho puede entenderse con carácter absoluto. Esto no quiere decir que tales elementos estén sujetos a la disponibilidad presupuestaria sino que sólo puede exigirse, constitucionalmente hablando, un contenido mínimo, no todos los contenidos posibles. No hay, en consecuencia, un derecho fundamental a disponer de las infraestructuras y técnicas sanitarias mejores del mundo, sino a recibir una asistencia sanitaria suficiente para la tutela del bien jurídico protegido. Desde la perspectiva señalada, algunos elementos que cabe asociar al elemento de disponibilidad del DPS encajan mejor en su contenido adicional que en su contenido mínimo. Aquí podemos incluir la mayor parte de las prestaciones que suelen asociarse a la idea de calidad de la asistencia sanitaria: derecho a la elección de médico, a la segunda opinión facultativa, así como una serie variada y todavía poco definida de facultades, que cabe encuadrar en el derecho a la comodidad en la asistencia sanitaria.

51 Para esta amplia jurisprudencia, muy casuística, vid., por todos, M. C. POLO SÁNCHEZ, Reintegro de gastos médicos y Estado del bienestar, Tirant lo Blanch, Valencia, 2001.

52 P. ej., STS (Social) de 17 de julio de 2000.

53 P. ej., STS de 21 de febrero de 1995 (Ar. 1168).

${ }^{54}$ La STS (Social) de 8 de noviembre de 1999 (Ar. 9416) quiso mantener la tesis tradicional ya bajo la vigencia del RD 63/1995, por considerar que subsistían las mismas razones que justificaban dicha tesis. Esta interpretación, loable por lo que implica de garantía del derecho fundamental (aunque más valiente hubiera sido plantear la cuestión de inconstitucionalidad contra el art. 9 LCC), creemos que rompe la literalidad de la norma, que sólo permite el reintegro en casos de urgencia vital. Así se pronuncian con claridad desde 2000 los Tribunales Superiores de Justicia e incluso, con alguna ambigüedad, la doctrina más reciente del propio Tribunal Supremo (STS —Social— de 4 de febrero de 2000). Vid., al respecto, J. Guerrero Zaplana, Las reclamaciones

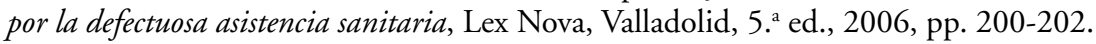

55 La regresión podría ser constitucional si se demostrara que existen formas de compensarla. Como después veremos en relación con las listas de espera, en la práctica no hay fórmulas alternativas que permitan dicha compensación. 
b) Accesibilidad económica o asequibilidad. Según la OG 14 la asistencia sanitaria debe estar al alcance de todos. Nuestro ordenamiento no reconoce con claridad la gratuidad de la asistencia sanitaria pero esta se ha impuesto en la práctica con carácter general, al menos para los sujetos que tienen reconocido este derecho mediante normas especiales; para los demás, los artículos 16.3 y 83 LGS prevén la «facturación». En la práctica, con este fundamento legal, persisten situaciones en las que ciudadanos españoles o ciudadanos extranjeros con residencia en España (en ambos casos, titulares del DPS) son atendidos por el SNS, pero se les cobra por ello. Se trata de un colectivo, según el Defensor del Pueblo, de unas 200.000 personas, que responden a situaciones heterogéneas, pero básicamente a la siguiente: no se encuentran en ninguno de los supuestos del artículo 100 LGS, según el cual «serán beneficiarios de la asistencia sanitaria» no todas las personas sino únicamente los trabajadores por cuenta ajena, los pensionistas y los familiares o asimilados de ambos, en todos los casos si se cumplen una serie de requisitos. Podría entenderse que este precepto ha quedado derogado (o ampliado) por la legislación sanitaria posterior, la cual, por un lado, desvincula asistencia sanitaria y seguridad social y, por otro, reconoce la titularidad universal (con la única excepción de los extranjeros no residentes) del DPS, pero la interpretación que sigue la Administración es más bien otra: la asistencia sanitaria reconocida por el artículo 100 LGSS es la asistencia sanitaria gratuita. En principio, la mayor parte del colectivo citado podría entrar en el ámbito de aplicación del Real Decreto 1088/1989, por el que se extiende la cobertura (léase la gratuidad) de la asistencia sanitaria de la Seguridad Social a las personas sin recursos económicos suficientes (los cuales se cifran en rentas iguales o inferiores en cómputo anual al salario mínimo interprofesional). Por ello, puede afirmarse con carácter general que, aun cuando se facturaran los servicios sanitarios prestados a personas excluidas de cobertura por la antigua normativa de la seguridad social, dicha facturación no contravendría el principio de asequibilidad, al presumirse que quienes perciben el salario mínimo interprofesional serán capaces de hacer frente a los gastos correspondientes. En todo caso, la práctica habitual es prestar la asistencia y facturar después, sin exigir el pago por adelantado. Llegados a este punto, debemos plantearnos si la excepción mencionada, prevista en la ley (pues el art. 100 LGSS y su normativa concordante no han sido derogados), resulta inconstitucional o simplemente injusta. El Defensor del Pueblo, que desde hace bastantes años viene denunciando la situación ${ }^{56}$, así como la escasa doctrina que se mueve en la misma línea

56 Vid., sobre todo, la Recomendación 29/2001 y, últimamente, el Informe de 2006, pp. 241-242. 
crítica $^{57}$ no acaban de decidirse con claridad al respecto. A nuestro juicio, si la asistencia sanitaria efectivamente se presta y si la facturación se realiza respetando el principio de asequibilidad, no se contraviene de manera frontal el artículo 43.1 CE. Sin embargo, se vulnera el artículo $14 \mathrm{CE}$, pues desde que la sanidad se financia por vía impositiva y no mediante cotizaciones, no hay justificación razonable para la diferencia de trato consistente en exigir el pago de la asistencia sanitaria (que no se exige a la amplia mayoría) al colectivo al que nos venimos refiriendo. La solución sólo puede venir ( $\mathrm{y}$ en esto coinciden tanto el Defensor del Pueblo como la doctrina citada) de la mano de una reforma de la legislación del Estado ${ }^{58}$ que anude con claridad titularidad del derecho y gratuidad de la asistencia sanitaria pública y elimine la obsoleta dependencia de esta de la seguridad social.

c) Extensión. Las prestaciones sanitarias exigibles conforman la parte más característica del contenido del DPS. El artículo 43.1 CE impone al respecto unas prestaciones mínimas, que deben resultar suficientes para dotar de efectividad a los bienes jurídicos que dan vida al derecho fundamental. Si bien ya hemos realizado una buena poda, al dejar fuera del artículo 43 los llamados condicionantes de la salud, todavía el ámbito de la enfermedad, el dolor y el sufrimiento resulta ser relativamente amplio y borroso, y por ello también lo es la frontera entre lo exigible y lo no exigible por el derecho fundamental. En realidad, los supuestos fronterizos son pocos (después aludiremos a la posición del Defensor del Pueblo al respecto) y sobre ellos podría llegarse a un acuerdo científico y social sin demasiada dificultad. Desde luego, resulta constitucional y razonable el criterio seguido por el RDCSC de excluir del contenido del derecho las prestaciones «que tengan como finalidad meras actividades de ocio, descanso, confort, deporte o mejora estética o cosmética, uso de aguas, balnearios o centros residenciales u otras similares» (art. 5.4 a).

Sea como fuere, la importancia de la labor del Parlamento en la determinación de las prestaciones es evidente, y quizás por ello la segunda frase del artículo

57 M. Hernández Bejarano (La ordenación sanitaria en España, Aranzadi, Pamplona, 2004, pp. 106-107), que distingue bien entre universalidad y gratuidad, señala que «estamos ante prestaciones básicas, esenciales, que tienen el carácter de mínimas y que, en la actualidad, deberían ser de reconocimiento gratuito a cualquier ciudadano", pero no aclara la naturaleza jurídica o moral de ese deber ser. Por su parte, Pemán Gavín (Asistencia..., cit., pp. 39, 99-100 y 170), pese a confundir universalidad y gratuidad, llega a afirmar la inconstitucionalidad de esta situación, pero sin citar siquiera los preceptos constitucionales vulnerados.

58 Erróneamente, HERNÁNDEZ BEJARANO (La ordenación..., cit., pp. 107-109) atribuye esta tarea al legislador autonómico. Con mejor criterio, PEMÁn Gavín (Asistencia..., cit., pp. 100, 155156 y 171), con quien coincidimos plenamente en este punto. 
43.2 CE introdujo simultáneamente un mandato al legislador y una reserva de ley en la materia, que sólo con la LCC ha sido cumplida.

Como se adelantó, la CE opta por un concepto de salud comprensivo de la salud individual y de la salud colectiva, de la asistencia en caso de enfermedad, en el amplio sentido del término, y de la prevención frente a la misma. Esta perspectiva, claramente asumida por la LGS, se proyecta en el diseño de las prestaciones de la LCC, que incluye la asistencia en caso de enfermedad en sentido estricto, pero también prestaciones de prevención y promoción de la salud, rehabilitación y reinserción o, en términos de su artículo 7.1, los «servicios preventivos, diagnósticos, terapéuticos, rehabilitadores y de promoción y mantenimiento de la salud». Llamamos la atención sobre la inclusión de prestaciones no típicamente asistenciales (sobre todo, art. 11), pues ponen de manifiesto que una parte (no sustancial, en todo caso) de la salud colectiva goza de una dimensión individual, y por tanto puede ser exigida con las típicas técnicas del derecho subjetivo.

La LCC fija las prestaciones sanitarias que conforman el contenido del DPS, lo que se traduce en un listado cerrado de prestaciones (arts. 7 a 19), que aporta dosis elevadas de estabilidad y seguridad jurídicas ${ }^{59}$, limitando la libertad de actuación del personal sanitario y la discrecionalidad judicial, sobre todo en comparación con la situación anterior. El Catálogo de Prestaciones de la LCC es concretado por una Cartera de Servicios Comunes, aprobada, siguiendo los criterios y el procedimiento específico del artículo 20 LCC, mediante el ya citado RDCSC. Dado el amplio margen de concreción que la LCC abre al reglamento y dada la trascendencia del mismo para la efectividad del derecho fundamental ${ }^{60}$, resulta criticable que no se hayan seguido en su elaboración mecanismos de participación ciudadana que vayan más allá de los generales de la $\mathrm{LPC}^{61}$.

59 Tras la decisión política de fijar por ley las prestaciones sanitarias se encuentran dos tendencias que sólo en apariencia resultan contradictorias: la superación del temor a la crisis económica y el interés por racionalizar el gasto, mediante la fijación estable de las prioridades (p. ej., art. 10.3). Desde el punto de vista constitucional, la primera tendencia es sumamente positiva y la segunda resulta razonable y, salvo que afecte al contenido del derecho fundamental (lo que no se ha demostrado, como veremos), también constitucional.

${ }^{60}$ Pese a ello, entendemos que no se vulnera la reserva de ley, dada la necesidad de flexibilizarla en materia de prestaciones.

${ }^{61}$ Con carácter general, P. DE LORA («El derecho a la protección de la salud», en Constitución $y$ derechos fundamentales, CEPC, Madrid, 2004, pp. 903-904) y, en el sentido del texto, J. VIDA FERNÁNDEZ, «Las prestaciones sanitarias del Sistema Nacional de Salud: catálogo de prestaciones y carteras de servicios», en La reforma del Sistema Nacional de Salud, Marcial Pons, Madrid, 2004, p. 64. 
Las Comunidades Autónomas pueden ampliar la Cartera de Servicios del RDCSC, teniendo en cuenta, en todo caso, los criterios de actualización exigidos a nivel nacional y que seguidamente veremos. La normativa vigente es claramente consciente de que esta determinación autonómica del contenido del derecho debe respetar el fijado a nivel nacional y que por tanto sólo puede servir para añadir nuevas prestaciones ${ }^{62}$. Dado el nivel de detalle al que se llega en el RDCSC, está claro que la normativa autonómica que fuera más allá de él se movería en el ámbito del contenido adicional del derecho fundamental, y que por tanto las eventuales diferencias entre Comunidades Autónomas en principio resultarían constitucionales.

En su momento aludimos a la naturaleza histórica y por tanto variable del concepto de salud, naturaleza que nuevamente encuentra reflejo en la determinación de las prestaciones concretas. En esta dirección, la LCC fija los grandes elementos de las nueve prestaciones que configura, que sólo pueden ser ampliadas por ley estatal (la técnica legislativa más correcta sería reformar la LCC), y ello tras el cumplimiento de los requisitos del artículo 10.3 (memoria económica e Informe del Consejo de Política Fiscal y Financiera) ${ }^{63}$. La ampliación («actualización», en los términos más comedidos del art. $21 \mathrm{LCC}$ ) permanente del contenido del derecho (que, mientras no se reforme la LCC, ha de referirse a alguna de las nueve prestaciones del Catálogo) viene dada, sobre todo, por la posibilidad de introducir nuevos servicios comunes (mediante Orden del Ministerio de Sanidad y Consumo, previo acuerdo del CISNS) o nuevas técnicas, tecnologías o procedimientos dentro de los servicios ya reconocidos (para lo que no se exige norma general alguna). Las cautelas establecidas en el artículo 21.3 dejan traslucir una cierta intención del legislador de impedir mejoras en el contenido del derecho, lo que resultaría contrario al principio de progresividad y a la misma naturaleza del DPS (nuevas enfermedades requerirán nuevos tratamientos). Sin embargo, el precepto no resulta inconstitucional, pues siempre queda la posibilidad de ampliación a nuevos servicios o técnicas que contribuyan a las finalidades descritas en el apartado a) del párrafo citado, las cuales coinciden, según vimos, con el bien jurídico protegido por el derecho fundamental. Una vez más hay que lamentar que la determinación normativa del procedimiento de actualización (art. 8 RDCSC) haya omitido todo mecanismo especial de participación ciudadana ${ }^{64}$.

${ }^{62}$ La doctrina es unánime al respecto. Vid., p. ej., J. VIDA FERNÁNDEZ, «Las prestaciones...", cit., pp. 57-58.

${ }^{63}$ Una nueva precaución frente al desbordamiento del gasto, que evidentemente no vincula al legislador futuro.

${ }_{64} \mathrm{El}$ art. 8.7 RDCSC, interpretado sistemáticamente, no incluye la posibilidad de solicitudes ciudadanas de actualización (que siempre cabrían, ex art. 29.1 CE). Vid., sin embargo, en Aragón, el Decreto 65/2007, cuyo art. 7.1 d) prevé esta forma de participación. 
Por razones de espacio, no podemos realizar aquí un estudio pormenorizado de las nueve prestaciones de la LCC y de su concreción actual en el RDCSC y en la normativa autonómica correspondiente, estudio este que seguramente excedería de lo estrictamente constitucional. Sin embargo, sí debe realizarse una valoración global de la tendencia legislativa, desde la perspectiva del principio de realización progresiva del DPS. En relación con este punto, debe hacerse obligada mención a la aportación al tema de PEMÁN GAVÍN, que, pese a su indudable valor, cae en una cierta contradicción, por cuanto este autor comienza afirmando «el carácter restrictivo con el que se abordan las modificaciones ampliatorias del catálogo de prestaciones» para reconocer después que se han producido «desarrollos ampliatorios» e incluso «un importante ensanchamiento [que se sigue produciendo] del contenido efectivo de no pocas de las prestaciones reconocidas» ${ }^{65}$.

Para conocer el estado actual de la cuestión, nada mejor que acudir a los Informes del Defensor del Pueblo. Pues bien, si analizamos despacio sus recomendaciones sobre la extensión de la asistencia sanitaria, observamos que las carencias (que no son pocas) demandadas por la Institución se refieren más bien a problemas, normalmente coyunturales, de disponibilidad (p. ej., déficit de servicios pediátricos en atención primaria, de servicios de reproducción asistida o de cuidados paliativos o insuficiente tratamiento de algunas enfermedades como las raras o poco frecuentes o el daño cerebral adquirido o de la rehabilitación de enfermos mentales), no tanto a la falta de previsión de determinadas prestaciones en el RDCSC. En definitiva, el grueso de las deficiencias de nuestro sistema sanitario, en lo que al catálogo de prestaciones se refiere, es más bien producto de la inactividad o ineficacia administrativa que de la omisión reglamentaria. Como excepción, el Defensor del Pueblo señala, «a título meramente de ejemplo», tres carencias del RDCSC: la lipodistrofia asociada a la infección por VIH, la atención podológica a diabéticos y la cirugía de reasignación de sexo. Dando por hecho que tales enfermedades no encuentran cabida, ni aun desde una interpretación flexible de su contenido, en el RDCSC, para afirmar la inconstitucionalidad reglamentaria (algo que el Defensor del Pueblo no llega expresamente a hacer) debería demostrarse que se trata de enfermedades importantes, que realmente afectan al bien protegido por el derecho fundamental, y para ello se precisaría de un cierto acuerdo científico y social.

Un tema importante y escasamente abordado por la doctrina es la forma de otorgamiento de las prestaciones normativamente definidas, pues en la práctica las decisiones competen al personal sanitario, el cual, pese a la ya aludida pérdi-

\footnotetext{
${ }^{65}$ J. Pemán Gavín, Asistencia..., cit., pp. 86-91.
} 
da de libertad, sigue disponiendo, como resulta inevitable e incluso positivo, de un amplio margen de actuación. Dentro del elemento de la extensión de la asistencia sanitaria debe incluirse, a nuestro juicio, el derecho al diagnóstico y tratamiento de las enfermedades incluidas en la cartera de servicios comunes, de forma adecuada a la lex artis ad hoc: en la mayor parte de los casos, una mala praxis (esto es, el incumplimiento de la lex artis) implicará vulneración del DPS. En nuestro ordenamiento y práctica sanitarias estamos todavía lejos de llegar a la crítica situación planteada en otros países, en la cual el personal sanitario puede negarse a prestar asistencia por falta de medios económicos. En nuestro sistema las prestaciones sanitarias están bastante definidas, son un derecho subjetivo y en principio no puede aducirse la escasez de recursos para su negación ${ }^{66}$. En supuestos excepcionales, el uso por el médico de determinadas técnicas (p. ej., trasplante de órganos) exige una autorización administrativa previa. Pues bien, creemos que incluso en estos casos quien deniegue el tratamiento no podrá aducir como argumento fundamental su excesivo coste (aunque en la práctica este pueda ser el motivo de fondo de la denegación) sino, en su caso, su no necesidad terapéutica.

d) Celeridad. Una pronta asistencia sanitaria es un elemento importante del contenido del derecho, y así se refleja en la opinión de los titulares del mismo, que sitúan con rotundidad las listas de espera como el problema principal de nuestro sistema sanitario. Sin embargo, la espera no es igualmente dañina en todos los casos y su grado de afectación al DPS dependerá del tipo de enfermedad, del momento de su avance, del modo en que cada paciente afronta su enfermedad y de muchos otros factores.

La demora en la asistencia sanitaria es seguramente un problema estructural del sistema de provisión pública y, en todo caso, añadimos ahora que se trata de un problema grave en nuestro país. Con carácter general, al menos mientras se mantenga vigente la actual configuración legal del reintegro de gastos, el DPS impone actuaciones positivas de los poderes públicos (obviamente, ante todo, del legislador) para paliar el problema. Una vez más, lo importante no es tanto el medio empleado como su eficacia real al servicio del fin que se pretende.

La celeridad de la asistencia es uno de los pocos elementos del DPS reconocidos expresamente como tales por la LCC. El artículo 4 b) reconoce el derecho de los ciudadanos «a recibir asistencia sanitaria en su Comunidad Autónoma de residencia en un tiempo máximo», a lo que el artículo 25.1 añade: «En el seno del Consejo Interterritorial se acordarán los criterios marco para garantizar un

${ }^{66}$ Recuérdese que hablamos ahora de la asistencia sanitaria en sentido estricto, dejando fuera el derecho al medicamento. 
tiempo máximo de acceso a las prestaciones del Sistema Nacional de Salud, que se aprobarán mediante Real Decreto. Las Comunidades Autónomas definirán los tiempos máximos de acceso a su cartera de servicios dentro de dicho marco». El artículo 25.2 excluye de esta garantía los transplantes y atención sanitaria ante situaciones de catástrofe.

El Real Decreto al que se refiere el precitado artículo 25.1 LCC no ha sido dictado en la fecha de cierre de estas páginas ${ }^{67}$. Dado el tiempo transcurrido, nos encontramos ante un supuesto claro de inactividad administrativa ilegal. Sin embargo, la mayor parte de las Comunidades Autónomas han dictado normas sobre la materia (normalmente, referidas a intervenciones quirúrgicas o a determinadas enfermedades), pero siguiendo modelos muy distintos ${ }^{68}$. A mi juicio, las diferencias en la normativa autonómica son demasiado acusadas, llegando a afectar al contenido mínimo del DPS. La responsabilidad principal (en la efectividad del DPS y en la igualdad sustancial en el ejercicio del mismo) recae sobre el poder reglamentario estatal, quien estando claramente obligado a fijar plazos máximos, no lo ha hecho. Esta obligación puede ser exigida, como parte del derecho fundamental, ante la jurisdicción contencioso-administrativa. La normativa debería seguir uno de los dos primeros modelos autonómicos expuestos,

${ }^{67}$ Días antes del la entrada en vigor de la LCC se dictó el RD 605/2003, por el que se establecen medidas para el tratamiento homogéneo de la información sobre las listas de espera en el SNS, norma que constituye un primer paso para la solución del problema pero que queda lejos de lo exigido por el art. 25.1 LCC.

${ }_{68}$ En el momento actual, pueden clasificarse en cuatro categorías: a) Fijación de uno o varios plazos máximos (como regla general, 180 días) de asistencia, transcurridos los cuales el paciente puede requerir la asistencia en un centro sanitario privado de su Comunidad (Andalucía - Decreto 209/2001- y Extremadura — Ley 1/2005—), en cualquier centro sanitario de España (Aragón, Decreto 83/2003), en un centro privado concertado (Baleares, Decreto 83/2006) o en un centro alternativo (Canarias — Orden de 15 de mayo de 2003 — Castilla-La Mancha —Decreto 9/2003 —, Murcia - Decreto 25/2006 - y País Vasco —Decreto 25/2006-). En estos ocho casos, la posibilidad de acudir a otro centro sanitario es configurada claramente como un derecho subjetivo. b) Opción esencial por el modelo anterior, pero utilizando cláusulas que evitan configurar un claro derecho subjetivo, dejando en manos de la discrecionalidad administrativa la decisión a tomar; así, se emplean fórmulas de salvaguarda como: el Servicio de Salud "podrá derivar» al paciente o "podrá autorizar al centro escogido» para que este trate al paciente (Cataluña, Decreto 354/2002), "podrá ofertar» al paciente otro centro (Madrid, Decreto 62/2004) o el paciente "podrá solicitar» centro privado y la Administración lo concederá «dentro de las disponibilidades presupuestarias» (Comunidad Valenciana, Decreto 97/1996). c) Determinación de planes de actuación para solventar el problema, sin fijación de plazos máximos ni garantías a favor de los ciudadanos. Es el caso de Cantabria (Decreto 116/2006) y Castilla-León (Acuerdo 261/2003). d) Ausencia total de normativa (Asturias y La Rioja) y regulación legal de la materia pero sin desarrollo reglamentario (Galicia Ley 7/2003, art. $133.1 \mathrm{u}$ ) - y Navarra — Ley Foral 12/1999—). 
pues el tercero se mueve en la lógica de los mandatos objetivos y no en la lógica de los derechos fundamentales, que es la que aquí corresponde.

\subsection{Intervenciones y limites}

En los apartados precedentes hemos descrito diversos supuestos de intervenciones (en el sentido amplio de la expresión, comprensivo de intervenciones en sentido estricto, regresiones y omisiones) sobre el DPS, prestando especial atención a las procedentes de los poderes legislativo y reglamentario estatales. $\mathrm{Al}$ gunas de estas intervenciones generales fueron sometidas a un análisis de constitucionalidad, con los resultados que se reflejan en el siguiente cuadro comparativo, que sintetiza ideas ya expuestas:

\begin{tabular}{|c|c|c|c|c|}
\hline $\begin{array}{l}\text { Elemento } \\
\text { del Derecho }\end{array}$ & Intervención & Finalidad & Proporcionalidad & Constitucionalidad \\
\hline $\begin{array}{l}\text { Disponibilidad } \\
\text { de la asistencia } \\
\text { sanitaria. }\end{array}$ & $\begin{array}{l}\text { Los arts. } 17 \text { LGS y } \\
9 \text { LCC implican } \\
\text { un retroceso sobre } \\
\text { el art. } 18 \text { del De- } \\
\text { creto } 2766 / 1967\end{array}$ & $\begin{array}{l}\text { Supuestamente, la } \\
\text { reducción de cos- } \\
\text { tes. }\end{array}$ & $\begin{array}{l}\text { No es proporcio- } \\
\text { nado retroceder } \\
\text { en materia social } \\
\text { sin justificación } \\
\text { alguna y sin ac- } \\
\text { ciones reductoras } \\
\text { del retroceso. }\end{array}$ & $\begin{array}{l}\text { Vulneración del art. } \\
43.1 \text { CE, por conexión } \\
\text { con el art. } 2.1 \text { PI- } \\
\text { DESC. }\end{array}$ \\
\hline $\begin{array}{l}\text { Accesibilidad de } \\
\text { la asistencia sani- } \\
\text { taria. }\end{array}$ & $\begin{array}{l}\text { El art. } 100 \text { LGSS } \\
\text { impone la cotiza- } \\
\text { ción a la Seguridad } \\
\text { Social para recibir } \\
\text { asistencia sanitaria. }\end{array}$ & $\begin{array}{l}\text { La finalidad de } \\
\text { vincular asistencia } \\
\text { sanitaria y Seguri- } \\
\text { dad Social no es } \\
\text { compatible con el } \\
\text { art. 43.1 CE. }\end{array}$ & & $\begin{array}{l}\text { La diferencia de trato, } \\
\text { al basarse en una fina- } \\
\text { lidad ilegítima, vulnera } \\
\text { el art. } 14 \text { CE. }\end{array}$ \\
\hline $\begin{array}{l}\text { Extensión de la } \\
\text { asistencia sanita- } \\
\text { ria. }\end{array}$ & $\begin{array}{l}\text { Omisión en el } \\
\text { RDCSC de la li- } \\
\text { podistrofia asocia- } \\
\text { da al VIH, de la } \\
\text { atención podológi- } \\
\text { ca a diabéticos y de } \\
\text { la cirugía de reasig- } \\
\text { nación de sexo. }\end{array}$ & $\begin{array}{l}\text { Supuestamente, la } \\
\text { reducción de costes } \\
\text { y la escasa impor- } \\
\text { tancia de esas en- } \\
\text { fermedades. }\end{array}$ & $\begin{array}{l}\text { Está en estudio la } \\
\text { cuestión. }\end{array}$ & ¿? \\
\hline $\begin{array}{l}\text { Celeridad de la } \\
\text { asistencia sanita- } \\
\text { ria. }\end{array}$ & $\begin{array}{l}\text { Omisión de des- } \\
\text { arrollo reglamenta- } \\
\text { rio estatal del art. } \\
25.1 \text { LCC (listas } \\
\text { de espera) }\end{array}$ & $\begin{array}{l}\text { Supuestamente, el } \\
\text { deber de las CCAA } \\
\text { de realizar dicho } \\
\text { desarrollo. Esta in- } \\
\text { terpretación no es } \\
\text { compatible con el } \\
\text { art. } 149.1 \mathrm{CE} \text {. }\end{array}$ & & $\begin{array}{l}\text { Omisión vulneradora } \\
\text { del art. } 43.1 \mathrm{CE} \text {. }\end{array}$ \\
\hline
\end{tabular}


Las intervenciones señaladas tienen un carácter general; en relación con las consideradas inconstitucionales, una vez realizadas las modificaciones normativas oportunas, dejarían de existir. Las intervenciones que suscitan las reclamaciones de los ciudadanos ${ }^{69}$ y que tienen un carácter permanente (dada la gran amplitud de sus posibles autores y de sus formas de aparición) son, sin embargo, las que proceden de los particulares y, sobre todo, de las Administraciones sanitarias (incluyendo el personal sanitario dependiente del SNS), en su faceta de creadoras de actos administrativos y otorgantes de prestaciones organizativas, financieras y materiales.

Las intervenciones no normativas pueden referirse a cualquiera de los elementos del contenido del derecho que hemos estudiado, en su doble consideración de derecho de defensa y derecho de prestación. En caso de resultar inconstitucionales, serán, además, contrarias a leyes o reglamentos, o a ambos tipos de fuentes a la vez. Como resulta prácticamente imposible enumerar las hipótesis concretas de intervención, nos contentaremos con señalar el método de análisis de su constitucionalidad, centrándonos únicamente en la faceta más característica del derecho, que es la prestacional.

La amplísima variedad de intervenciones posibles, a la vista de las reclamaciones planteadas ante el Defensor del Pueblo y ante los tribunales, se reduce, en su mayoría (la casuística es, por supuesto, mucho más rica) a dos grandes tipos de supuestos:

a) Por parte de la Administración sanitaria, falta de disponibilidad o de celeridad suficientes, en cuyo caso lo habitual es que el ciudadano acuda a otro centro sanitario y exija después el reintegro de los gastos ocasionados, en las circunstancias en las que ello es legalmente posible en el momento actual (sobre todo, urgencia vital y agotamiento de los plazos de espera previstos en determinadas Comunidades Autónomas). En estos casos (que son los que suelen llegar a los tribunales pero que sólo suponen una pequeña parte de las intervenciones que se producen en la realidad), la intervención se materializa en el acto administrativo que rechaza el reintegro.

Ningún límite constitucional puede justificar estas intervenciones. Como ya dijimos en relación con la disponibilidad ( $\mathrm{y}$ resulta aplicable con carácter gene-

${ }^{69}$ Debe destacarse, sin embargo, que también en los supuestos de inconstitucionalidad normativa que hemos detectado, cabe la reclamación individual: en los casos de leyes inconstitucionales, solicitando al juez el planteamiento de la cuestión de inconstitucionalidad; en el caso del reglamento inconstitucional, solicitando su nulidad ante la jurisdicción contencioso-administrativa y en el caso de la omisión reglamentaria, exigiendo la adopción del reglamento correspondiente ante esta misma jurisdicción. 
ral), la Administración no puede escudarse en razones presupuestarias para negarse a prestar la asistencia sanitaria necesaria para garantizar el bien protegido por el artículo 43.1 CE.

b) Por parte del personal sanitario adscrito al SNS, negativa al tratamiento médico (rechazo inicial del paciente, no envío al especialista, no envío a un centro de referencia, negativa a prescribir los medicamentos adecuados, alta no consentida) o tratamiento médico deficiente, inferior a los parámetros exigidos por la lex artis ad hoc. Normalmente, el paciente reclama, por la vía de la responsabilidad patrimonial, tras sufrir un daño a su salud, muchas veces ya irreparable. En estos supuestos (haya o no daño) nos encontramos ante una intervención fáctica (no ante un acto administrativo), consistente en un determinado comportamiento médico, que presenta formas variadas (desde una mera negativa verbal hasta una constancia en la historia clínica). Tampoco creemos que exista aquí límite constitucional alguno que pueda justificar la negativa al tratamiento.

En relación con lo antedicho, la lectura de la jurisprudencia sobre casos de denegación de asistencia sanitaria puede resultar engañosa, dado que, por razones estructurales, a los tribunales no llegan la gran mayoría de este tipo de problemas. Al respecto, quizás resulte más iluminadora la lectura de los Informes del Defensor del Pueblo. Entre los pocos casos relatados con algún detalle por esta institución ${ }^{70}$, haremos mención, para corroborar las tesis que venimos manteniendo, a la denegación de la fecundación in vitro a una pareja, por la unidad de reproducción asistida del Hospital de Valdecilla, de Santander ${ }^{71}$. Inicialmente, la unidad decidió que médicamente era necesario realizar el tratamiento señalado. Más adelante, ante la existencia de listas de espera en la unidad, comunicó a la pareja que el tratamiento no se realizaría, dado que previamente había tenido un hijo natural. Como se advierte, en el caso existe un problema general de celeridad, aunque la queja se produce no por este motivo sino por negativa de tratamiento (supuesto que hemos encajado en el elemento de extensión del derecho). El argumento utilizado por el personal sanitario para no realizar el tratamiento no está previsto en la ley, carece de fundamento constitucional y pretende encubrir la motivación principal del rechazo, la falta de medios. La respuesta del Defensor del Pueblo (que hace frente - y resulta significativo- no a la motivación expresa sino a la motivación implícita de la intervención) es clara, y se

${ }^{70} \mathrm{Al}$ investigador se le plantea un problema de acceso a la información, pues los casos estudiados por el Defensor del Pueblo suelen ser expuestos en sus Informes anuales de manera muy sintética.

${ }^{71}$ Recomendación 52/2006, de 26 de junio de 2006. 
mueve en la línea de cuanto vengo defendiendo (el DPS como derecho fundamental): «Esta Institución no puede compartir, en modo alguno, el criterio sustentado [por la unidad de reproducción asistida] para justificar la exclusión de una prestación sanitaria que, a tenor del marco legal vigente en la materia, debe ser facilitada directamente a las personas y financiada con cargo a los fondos estatales adscritos a la sanidad, con fundamento en razones de organización y funcionamiento de los servicios sanitarios, como es la extensión de las listas de espera».

El análisis del fundamento, contenido y límites del DPS ha demostrado que los derechos fundamentales sociales no son sustancialmente distintos a los derechos fundamentales liberales y que la dogmática de estos resulta aplicable a aquellos.

\section{Title}

The social fundamental rights and the protection of the health

\section{Resumen}

La dogmática de los derechos fundamentales sociales es todavía una tarea pendiente en España. Para desmontar los prejuicios que todavía dominan en torno a esta categoría, se hace preciso comenzar aclarando los presupuestos de cualquier dogmática de los derechos constitucionalmente adecuada: estructurales y materiales (Constitución orgánica, internacional, económica y financiera y Constitución de los derechos), así como la concepción de los principios (dignidad, Estado social, igualdad) que se mantiene. La explicitación de estos presupuestos lleva al autor a considerar que los derechos fundamentales sociales no son sustancialmente distintos a los derechos liberales. Como ejemplo, el estudio del derecho fundamental a la protección de la salud demuestra que el modelo de análisis de los derechos liberales (fundamento, contenido, intervenciones y límites) es aplicable a los derechos sociales.
Abstract
The constitutional doctrine of social rights is still a challenge in Spain. To remove the prejudices which still dominate on this topic, it is ne- cessary to begin by clarifying the assumptions of any doctrine of the rights constitutionally adequate, structural and materials (Constitution of the power, international Constitution, economic and financial Constitution, rights-based Constitution) and the design principles 
(human dignity, welfare state, real liberty, equality) is maintained. The explicitness of these assumptions leads the author to conclude that the social (fundamental) rights are not substantially different from the liberal rights. As an example, the study of the fundamental right to health shows that the model analysis of the liberal rights (foundation, content, damages and limits) is applicable to social rights.

\section{Palabras clave}

Derechos sociales.- Derecho a la salud

\section{Key words}

Social rights.- Right to health 